\title{
Are Technological Terms Seductive? The Effect of Technological Terms on Persuasion
}

\author{
Keli Saporta \\ Correspondence: Keli Saporta, Israel. E-mail: kelisa@openu.ac.il \\ Received: November 13, 2019 \\ Accepted: February 3, 2020 \\ Online Published: February 17, 2020 \\ doi:10.11114/bms.v6i1.4723 \\ URL: https://doi.org/10.11114/bms.v6i1.4723
}

\begin{abstract}
Most claims in marketing communication take the form of causal claims stating that using a certain product (the cause, e.g., "Fresh Air, the electronic device") produces a certain benefit (the effect, e.g., "purifies the air at home"). Marketers acknowledge (and studies show) that providing an explanation on the mechanism by which the product produces the effect fosters persuasion. Yet, instead of providing the specific mechanism (e.g. "it purifies the air at home by reducing dust parcels in the air"), they often use general technological terms. Thus, instead of explaining, "Fresh-Air purifies the air at home by reducing dust particles in the air," they "explain" that the product purifies the air by "applying a new algorithm." We call explanations that use general technological terms pseudo explanations, because they follow the same structure, but they lack the crucial element that enables persuasion - they are not content specific.
\end{abstract}

Although using pseudo explanations is a common practice in marketing, no studies have examined if they affect persuasion. In two studies, we exposed participants to causal claims for various products in several formats, and asked them to indicate the probability that they would purchase the product if they needed it. Generally, results show persuasion was the same for pseudo explanations as for the claim alone, when both were less persuasive than mechanistic explanations.

Consumers are sensitive to the fact that pseudo explanations do not really explain the mechanism. Thus, whereas pseudo explanations do not affect persuasion, mechanistic explanations do.

Keywords: mechanism, explanation, scientific terms, technological terms, mechanistic-explanation

\section{Introduction}

Marketers often expose consumers to causal claims, stating a certain cause, C (e.g., "Fresh Air," an electronic device), produces a certain effect, E (e.g., purifies the air at home). To foster persuasion, marketers often try to explain how the product produces the effect, by using general technological phrases such as "special algorithm," "a new formula," "a new technology," and so on. Studies show that providing a mechanistic explanation - an explanation of the process by which the product (the cause) produces the benefit (effect) (e.g., "by reducing dust particles in the air")-fosters persuasion (e.g., Anderson, 1980; Fernbach, Sloman, Louis, \& Shube, 2013; Saporta-Sorozon, 2018). Yet technological terms are not mechanistic explanations (Walsh \& Sloman, 2011) but rather pseudo explanations (hereafter, PE). The reason is that they follow the structure of a mechanistic explanation (cause -> mechanism $\rightarrow$ effect), ${ }^{1}$ but because they are general, they lack one of the very basic properties that characterize mechanistic explanations - content specificity (Ahn et al., 1995).

The use of general technological terms (PEs) in marketing communication is prevalent. Yet studies that examine whether they affect persuasion do not exist. The purpose of the present study is to fill this gap. Specifically, in the present study, we examine whether using PEs as part of a causal message in marketing communication is inferior to, superior to, or as persuasive as mechanistic explanations.

Obviously, using PEs instead of providing the mechanism might seem beneficial for the marketer for several reasons. Such terms seem innovative and professional and, above all, do not require the marketer to make any special effort to

\footnotetext{
${ }^{1}$ In a pilot study, we examined a sample of causal messages that use general technological terms. Most of them use technological terms as a way to explain how the product produces the benefit.
} 
find the specific mechanism that suits the focal causal claim. Thus, if using such PEs has the same positive effects as specifying a mechanism, why bother to search for the specific appropriate mechanism? The marketer can use such terms for almost any product. The present study is a step toward answering this question.

\subsection{Mechanistic Explanations}

\subsubsection{Definition of Mechanistic Explanation}

A mechanistic explanation involves the existence of intermediate variables (M) that lie on a spatio-temporal contiguous path from cause to effect (Fernbach et al., 2013; Walsh \& Sloman, 2011). A causal statement that specifies a mechanism can appear in different levels of detail, from very short (only one mediator) to very long (several mediators) (Einhorn \& Hogarth, 1986; Walsh \& Sloman, 2011).

\subsubsection{The Centrality of Mechanistic Explanations - A Literature Review}

A large body of studies demonstrates that explanations play a central role in our cognition and thus have many positive effects. People seek for information on explanations when trying to understand events (Ahn et al., 1995). They recruit explanations to help them justify, argue, and make sense of their claims (Glassner, Weinstock, \& Neuman, 2005; Kuhn, 2001). People perceive the probability of causal claims as higher when they need to explain them (Anderson, Lepper, \& Ross, 1980). Causal attributions rely on peoples' understanding of the process - the causal mechanism - involved in bringing about the outcome (Walsh \& Sloman, 2011).

Mechanistic explanations have many positive effects, such as enhancing the probability of the causal-claim acceptance (Anderson 1980; Walsh \& Sloman, 2011), fostering conceptual coherence (Murphy \& Medin, 1985; Patalano, Chin-Parker, \& Ross, 2006; Saporta-Sorozon, 2018), fostering a sense of understanding (Ahn, Novick, \& Kim, 2003; Saporta-Sorozon, 2018) and satisfaction (Gopnik, 2000), and increasing willingness to purchase the product (Fernbach et al., 2013; Saporta-Sorozon, 2018).

\subsubsection{Explanations and Content Specificity}

Researchers agree that previous causal knowledge plays a central role in the definition of a good explanation (Ahn et al., 1995; Einhorn \& Hogarth, 1985; Lombrozo, 2006; Saporta-Sorozon, 2018). People are actively engaged in trying to explain the occurrence of events.

Ahn et al. (1995) claim the causal-attribution process is content specific. For a certain content, people know a set of mechanisms; when in the process of causal attribution, they try to figure out whether a particular mechanism is appropriate (Ahn et al., 1995). Thus, while searching for an explanation, they consider only a subset of explanations - those that are congruent with previous knowledge (Ahn et al., 1995; Lombrozo, 2006). Consistent with this assertion, Kendeou and Van den Broek (2007) found that previous knowledge affects the process in which participants are engaged while trying to understand scientific texts. Explanations that are congruent with previous knowledge are good explanations, because they enable accommodation of the novel information to those beliefs (Ahn et al., 1995; Lombrozo, 2006; Saporta-Sorozon, 2018) and thereby facilitate the use of many cognitive functions.

\subsection{Pseudo Explanations}

\subsubsection{Technology and General Technological Terms vs. Science and Scientific Terms}

Many websites and dictionaries agree that technology is a body of knowledge devoted to creating tools, processing actions, and extracting products, in order to simplify our lives. Although technology sometimes refers to science, technology and science are different subjects. Technology sometimes involves the application of scientific knowledge for practical purposes. Thus, when using the phrase "technological terms," we do not refer to scientific terms but rather to general words that try to give the impression that the development of the focal product involves sophisticated procedures.

\subsubsection{Pseudo-Explanations vs. Mechanistic Explanations}

Using general technological phrases such as "a special algorithm," "a new technology," "an active ingredient," and so on is common in marketing communication. In the present study, we refer to using such terms as a way to explain how the product produces the effect as a pseudo explanation. The reason is that they follow the same structure as mechanistic explanations (c->m->e), but rather than specifying the mechanism that suits the focal content, they use general terms that can fit any content. Because the positive effects of mechanistic explanations occur due to being content specific whereas PEs are not, we expect PEs to be less persuasive than causal claims that include mechanistic explanations. Moreover, because PEs do not really add information that may facilitate persuasion, we expect them to be as persuasive as the causal claim alone (hereafter, CA). Notice that for a mechanistic-explanation to persuade the focal mechanism must be specific and its claimed effect must be congruent with previous knowledge. Thus, if the ad claims, "Fresh Air purifies the air at home," an explanation that includes the mechanism "by reducing dust particles in the air" would be persuasive, because its effect is congruent with previous knowledge. Differently, including the mechanism "by reducing 
humidity in the air" would not be persuasive or even impair persuasion, because although it is specific, it is incongruent with previous knowledge.

\subsection{Hypotheses}

To sum up, we hypothesize the following:

Hypothesis 1: The sense of understanding and willingness to purchase the product will be the highest when the causal argument provides an explanation that constitutes a mechanism variable that is congruent with previous knowledge.

Schematically: congruent mechanism $(\mathrm{CM})>$ incongruent mechanism (IM), pseudo explanation (PE), claim alone (CA).

Hypothesis 2: The sense of understanding and willingness to purchase the product will be similar for general technological terms, claim alone, and explanations that include a mechanism that is not congruent with previous knowledge.

Schematically: $\mathrm{IM}=\mathrm{PE}=\mathrm{CA}$.

Hypothesis 3: The degree of fit of the explanation with previous knowledge mediates the effect of the kind of explanation (CM vs. IM and CM vs. PE) on sense of understanding and willingness to purchase the product.

\section{Study 1}

The purpose of study 1 was to check if PEs are as good as CMs, or are as poor as IMs and have no advantage over CAs. We introduced each participant to five products in one of the four versions of kind of information.

\subsection{Method}

\subsubsection{Participants and Design}

We presented 77 undergraduates (males $\left.=54.5 \%, M_{\text {age }}=41.09 ; S D_{\text {age }}=15.78\right)$ with a Qualtrics web-based questionnaire for course credit, in a within-subjects design. Each participant read a description of each of five products. For each product, the description included one of the four kinds of information: CM, IM, PE, or CA. We randomly assigned participants to a combination of the specific product and the kind of information.

\subsubsection{Materials, Measures, and Procedure}

We exposed each participant to the five products in one of the experimental conditions. Table 1 presents the products and the four statements for each.

Table 1. The information participants saw in each condition for the five products

\begin{tabular}{|c|c|c|c|c|}
\hline The Product & CA & $\mathrm{CM}$ & IM & PE \\
\hline $\begin{array}{l}\text { Fresh Air the } \\
\text { Electric } \\
\text { Device }\end{array}$ & $\begin{array}{l}\text { The electric device } \\
\text { that purifies the air } \\
\text { at home }\end{array}$ & $\begin{array}{l}\text { by reducing dust } \\
\text { particles in the air }\end{array}$ & $\begin{array}{l}\text { by reducing the } \\
\text { humidity in the air }\end{array}$ & $\begin{array}{l}\text { by applying a special } \\
\text { algorithm }\end{array}$ \\
\hline $\begin{array}{l}\text { Express } \\
\text { sticker }\end{array}$ & $\begin{array}{l}\text { The medical glue } \\
\text { that releases sore } \\
\text { muscles }\end{array}$ & $\begin{array}{l}\text { by increasing blood } \\
\text { flow in the muscle area }\end{array}$ & $\begin{array}{l}\text { by increasing fluid } \\
\text { flow to the muscle } \\
\text { area }\end{array}$ & $\begin{array}{l}\text { by employing an active } \\
\text { ingredient that works in the } \\
\text { muscle area }\end{array}$ \\
\hline drink & $\begin{array}{l}\text { With the natural } \\
\text { ingredients that } \\
\text { produces alertness }\end{array}$ & $\begin{array}{l}\text { by stimulating the } \\
\text { nervous system }\end{array}$ & $\begin{array}{l}\text { by stimulating the } \\
\text { skeletal system }\end{array}$ & $\begin{array}{l}\text { by activating an innovative } \\
\text { formula }\end{array}$ \\
\hline $\begin{array}{l}\text { Alpha } \\
\text { moisturizer } \\
\text { cream }\end{array}$ & $\begin{array}{l}\text { The moisturizer that } \\
\text { prevents skin } \\
\text { dehydration }\end{array}$ & $\begin{array}{l}\text { by increasing the oily } \\
\text { layer in the skin of the } \\
\text { body. }\end{array}$ & $\begin{array}{l}\text { by increasing the } \\
\text { skin's contact with } \\
\text { the air. }\end{array}$ & $\begin{array}{l}\text { by using a unique ingredient } \\
\text { that works on the skin of the } \\
\text { body }\end{array}$ \\
\hline $\begin{array}{l}\text { Witty Food } \\
\text { cling wrap }\end{array}$ & $\begin{array}{l}\text { The cling wrap that } \\
\text { keeps the food fresh }\end{array}$ & $\begin{array}{l}\text { by reducing contact } \\
\text { with the air }\end{array}$ & $\begin{array}{l}\text { by reducing contact } \\
\text { with the light }\end{array}$ & $\begin{array}{l}\text { by applying an innovative } \\
\text { technology }\end{array}$ \\
\hline
\end{tabular}




\subsubsection{Measures}

After participants saw each ad, we measured the following:

(a) Explanations' reasonability (manipulation check). Participants rated the reasonability of the explanations, using a 6-point scale ( 1 = does not make sense at all, 6 = completely makes sense $)$.

(b) One's sense of understanding. Participants rated their understanding on a 6-point scale $(1=$ do not understand at all, $6=$ completely understand $)$.

(c) Willingness to purchase the product. Participants rated their willingness to purchase the product (if they needed such a product), using a 6 -point scale $(1=$ definitely not, $6=$ definitely yes $)$.

(d) Consistency of the information given with previous knowledge. Participants rated how well the information fit with their previous knowledge, using a 6-point scale $(1=$ does not fit at all, $6=$ completely fits $)$.

\subsection{Results}

Table 2 and Figures 1a, b, and c present the means of the four experimental conditions (CM, IM, PE, and CA) for each of the measures: reasonability (manipulation check), understanding, and willingness to purchase (dependent variables), and fit with previous knowledge (the proposed mediator). For each measure, we checked the differences between the four conditions by using the HELMET test for contrasts. This test compares each level with the average of the "preceding" ones. Because we have four conditions (CM, IM, PE, and CA) and we ordered them according to the hypotheses, the following three comparisons result: $\mathrm{CM}$ versus the average of IM, PE, and CA; IM versus the average of PE and CA; and PE versus CA. To verify that the difference in favor of the CM condition is not due to the averaging of the other three conditions, we also checked the difference between CM and the condition that received the highest average. Table 2 presents the results.

Table 2. Study 1 Means and standard deviations of the four experimental conditions (CM, IM, PE, and CA) in reasonability, understanding, willingness to purchase, and fit with previous knowledge, including the results of the contrasts

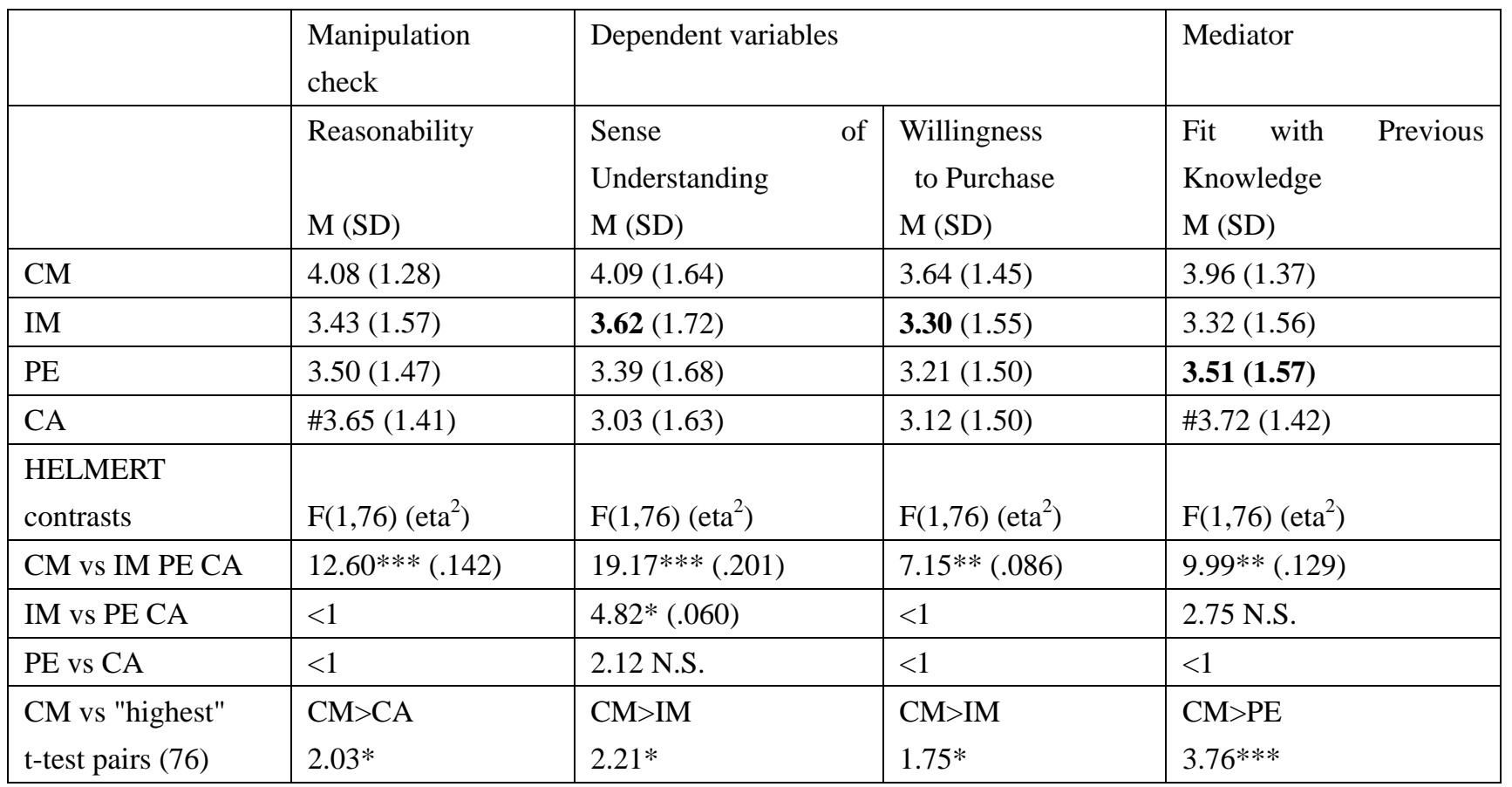

${ }^{*} p<.05 * * *, p<.001$, \# not relevant, because a claim is not "not reasonable" or contradicts previous knowledge. We include these means in the table to provide all of the data. 
a.

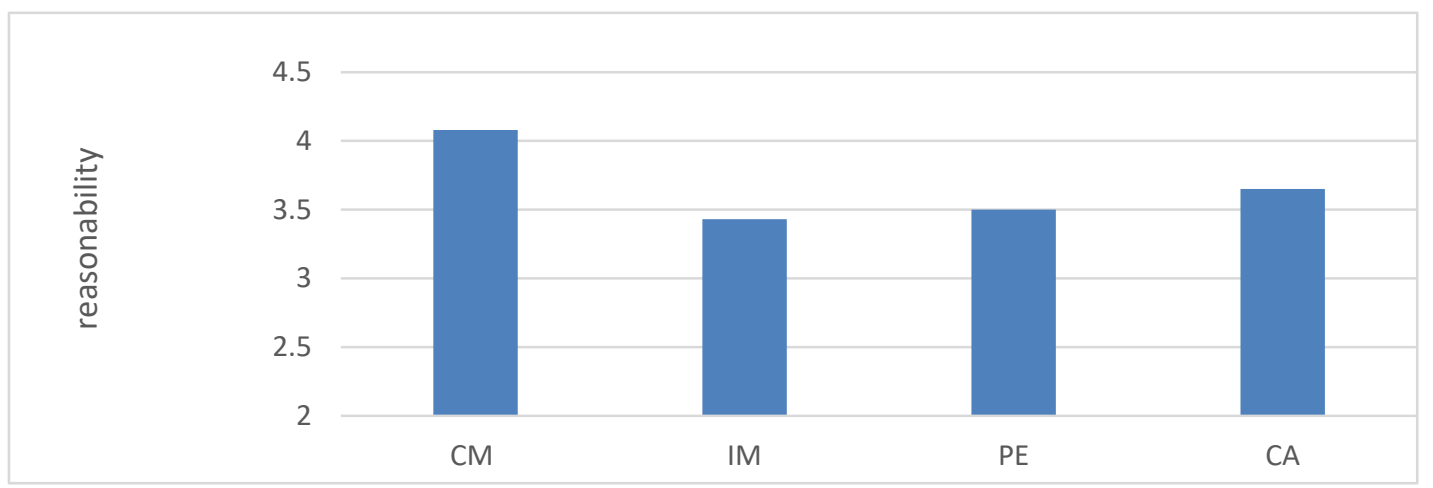

b.

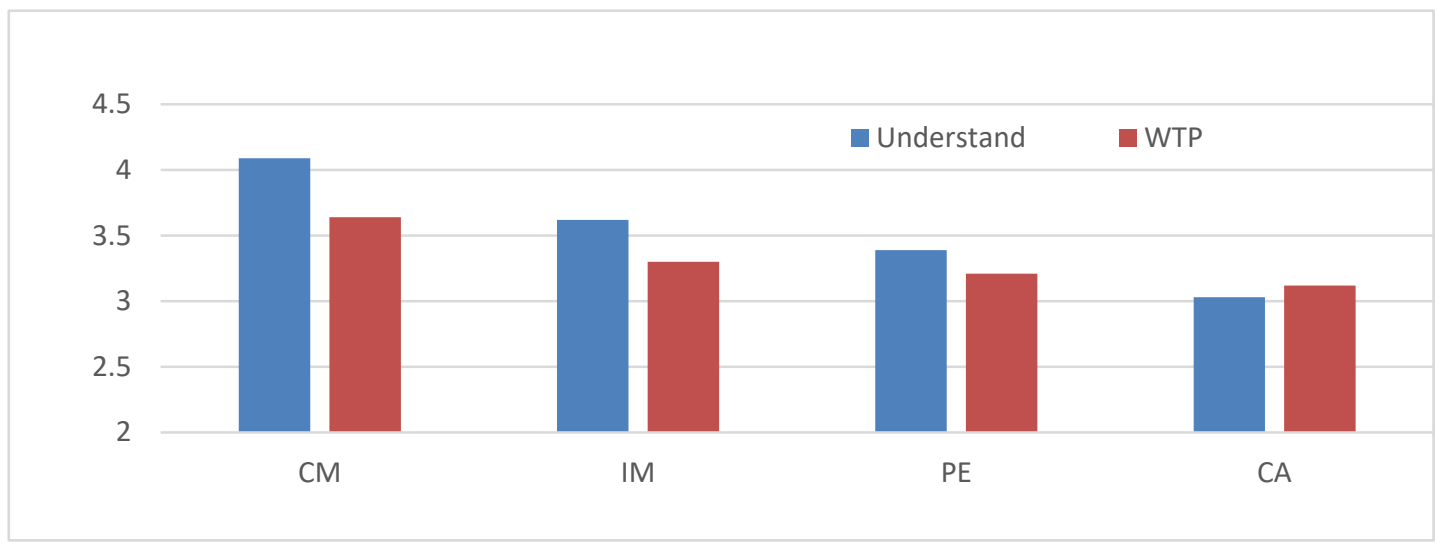

c.

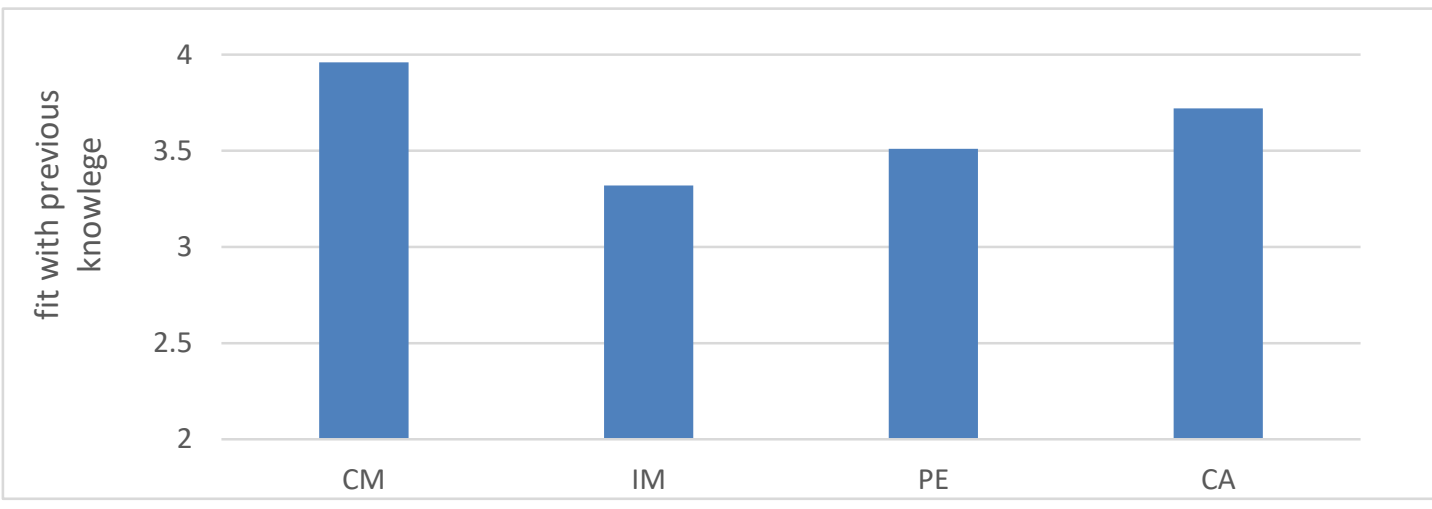

Figure 1. Study 1. Ratings of reasonability (a), understanding and willingness to purchase the product (b), and fit with previous knowledge (c), as a function of kind of information

\subsubsection{Manipulation Check and Fit With Previous Knowledge}

As expected (see Table 2 and Figures 1a and 1c), participants perceived CM as more reasonable and as fitting more with previous knowledge than IM and PE when the last two conditions did not differ. Notice the comparison with CA for these two measures is not relevant, because we do not expect a causal claim to be "unreasonable" or to contradict previous knowledge. Nevertheless, the mean of CA for these two measures was lower than CM.

\subsubsection{Hypotheses 1 and 2}

As can be seen in Table 1, as predicted (hypothesis 1), sense of understanding and willingness to purchase the product were the highest when the causal argument provided an explanation that constitutes a mechanism variable that is congruent with previous knowledge (CM> IM, PE, CA). Also, as predicted (hypothesis 2), sense of understanding and willingness to purchase the product were similar for PE and explanations that included a mechanism variable that was not congruent with previous knowledge and claim alone (IM=PE=CA).

\subsubsection{Mediation Analysis}

We hypothesized (hypothesis 3 ) that the degree of fit of the information with previous knowledge mediates the effect of kind of information (CM vs. IM and CM vs. PE) on sense of understanding and willingness to purchase the product. 
To examine the mediating role of fit with previous knowledge, we used the PROCESS macro based on Model 4 , proposed by Hayes (2013) (5,000 bootstrap samples). We performed the analysis separately for each of the outcome variables (sense of understanding and willingness to purchase), for two separate comparisons of experimental conditions: CM versus IM and CM versus PE. Specifically, we regressed CM versus IM or CM versus PE as the independent variable, and fit with previous knowledge as the mediators on sense of understanding or willingness to purchase (WTP).

Regarding the first set of mediation analyses (CM vs. IM), in line with hypothesis 3, we found that fit with previous knowledge mediated the effect of kind of information on sense of understanding $(\beta=-.36, S E=.11$, CI 95\%: -.58 to -.14$)$ and willingness to purchase $(\beta=-.27, S E=.08$, CI $95 \%$ : -.44 to -.11$)$. Figure 2 presents the results of these two mediation analyses.

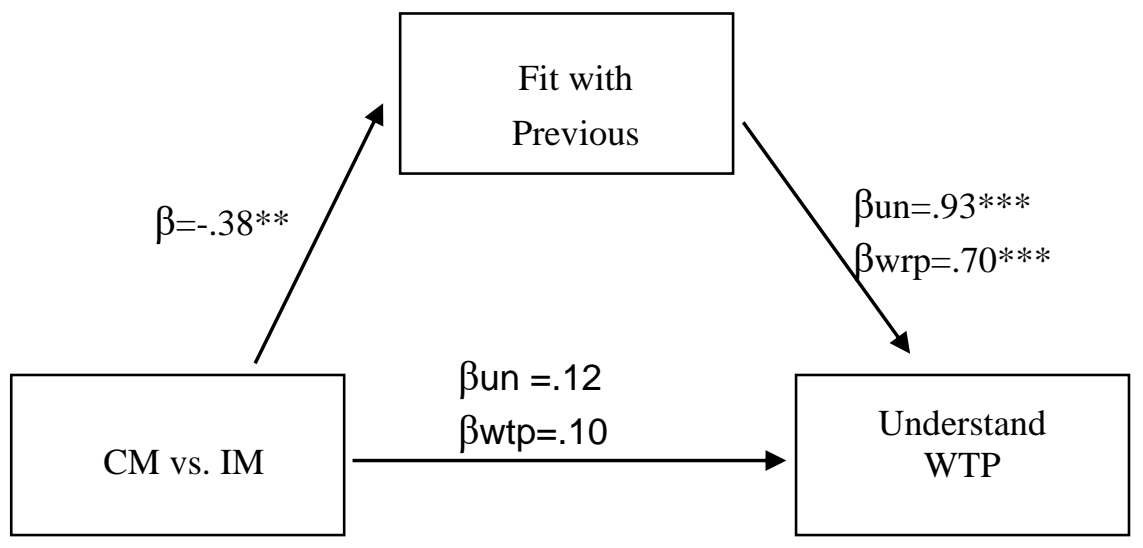

Figure 2. The effect of kind of information (CM vs. IM) on understanding and willingness to purchase, mediated by fit with previous knowledge

$* * \mathrm{p}<.01 ; * * * \mathrm{p}<.001$

Regarding the second set of mediation analyses (CM vs. PE), in line with hypothesis 3, we found that fit with previous knowledge mediated the effect of congruency on sense of understanding $(\beta=-.20, S E=.07$, CI 95\%: -.34 to -.07) and willingness to purchase $(\beta=-.15, S E=.05$, CI $95 \%$ : -.26 to -.05). Figure 3 presents the results of these two analyses.

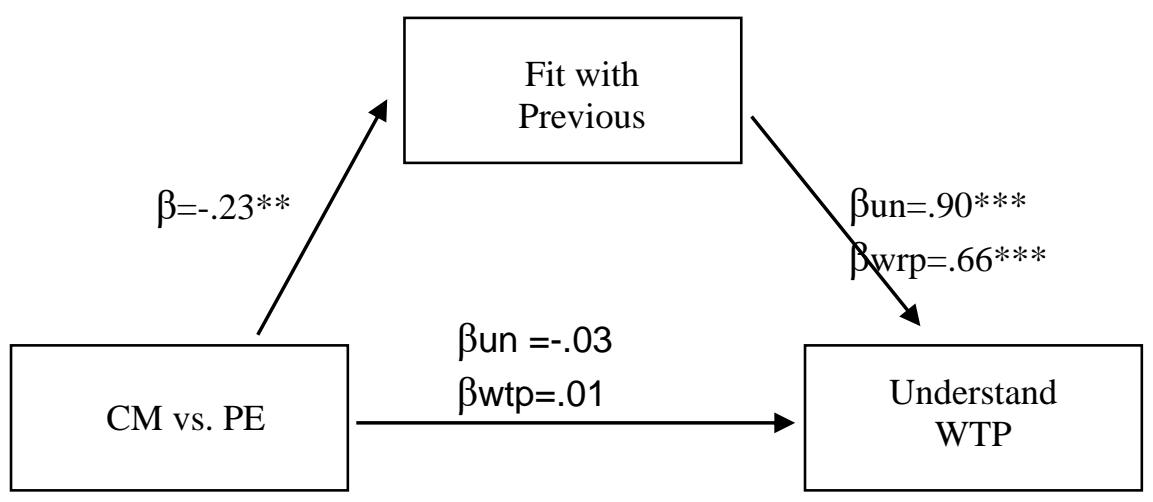

Figure 3. The effect of kind of information (CM vs. PE) on understanding and willingness to purchase, mediated by fit with previous knowledge

$* * \mathrm{p}<.01 ; * * * \mathrm{p}<.001$

\subsection{Discussion}

In study 1 , we demonstrated that PEs are a poor way to persuade consumers. Results show CM is the most persuasive when PEs are as bad as IMs and add nothing over the CA.

\section{Study 2}

The materials of study 1 included mechanisms concerning systems about which people have some knowledge. For 
example, people generally know eliminating dust particles can help purify the air, whereas reducing humidity cannot. Similarly, from past knowledge, people believe increasing blood flow to a sore muscle can help reduce the pain, whereas increasing water flow cannot.

The results of study 1 demonstrated that information about the mechanism outperformed PE, but only if it was congruent with previous knowledge. The question is what happens when the information the consumer receives concerns mechanisms he/she does not know. Maybe in that case, PE will be better. Specifically, because the consumer does not recognize the mechanism, mentioning it adds little valuable information that can help him/her judge the product, whereas using technological terms - although general - may add some relevant information.

To check this possibility, we designed study 2, in which we presented four new products (e.g., "the magic egg that increase the shelf life of fruits and vegetables"). We presented each product in one of four possible formats of kinds of information: CA, PE (e.g., "by using $\mathrm{WE}^{2}$ technology"), an unknown true mechanism (TM) (e.g., "by absorbing the ethylene gas they emit"), and an unknown false mechanism (FM) ("by absorbing the prion gas they emit").

Because studies show that using neuroscience explanations has a "seductive allure" (Weisberg, Taylor, \& Hopkins, 2015; Giattino, Kwong, Rafetto, \& Farahany, 2019), we expected that providing scientific mechanism whether true or false would be more persuasive than providing technological terms (PE).

We hypothesized the following:

Hypothesis 4: The sense of understanding and willingness to purchase the product will be higher for unknown mechanisms (whether true or false) than for PEs and CA. Schematically: TM, FM > PE, CA.

Hypothesis 5: The sense of understanding and willingness to purchase will be similar for the true mechanism and the false mechanism (schematically: $\mathrm{TM}=\mathrm{FM}$ ) and for PEs and CA (schematically: $\mathrm{PE}=\mathrm{CA}$ ).

\subsection{Method}

\subsubsection{Participants and Design}

One hundred undergraduates (males $=50 \%$, Mage $=42.00$; SDage $=15.37)$ took part in the study via a Qualtrics web-based questionnaire for course credit, in a within-subjects design. Each participant read a description of each of four products, and for each product, the description included one of the four kinds of information: unknown true mechanism (TM), unknown false mechanism (FM), PE, and CA. We randomly assigned participants to the combination of the specific product and the kind of information.

\subsubsection{Materials, Measures, and Procedure}

We exposed each participant to the four products in one of the information conditions (see Table 3).

Table 3. The information participants saw in each condition for the four products

\begin{tabular}{|c|c|c|c|c|}
\hline The Product & CA & TM & FM & $\mathrm{PE}$ \\
\hline The Magic Egg & $\begin{array}{l}\text { The magic egg includes } \\
\text { minerals that help } \\
\text { increase the shelf life of } \\
\text { fruits and vegetables }\end{array}$ & $\begin{array}{l}\text { by absorbing the } \\
\text { ethylene gas they } \\
\text { emit }\end{array}$ & $\begin{array}{l}\text { by absorbing the } \\
\text { prion gas they } \\
\text { emit }\end{array}$ & by WE technology \\
\hline $\begin{array}{l}\text { The cover for a } \\
\text { mobile phone }\end{array}$ & $\begin{array}{l}\text { The cover for a mobile } \\
\text { phone that includes a thin } \\
\text { copper mesh that prevents } \\
\text { cellular radiation }\end{array}$ & $\begin{array}{l}\text { by creating } \\
\text { "Faraday Cage". }\end{array}$ & $\begin{array}{l}\text { by creating } \\
\text { "Gauss Cage". }\end{array}$ & $\begin{array}{l}\text { using a new BETA } \\
\text { algorithm }\end{array}$ \\
\hline Food supplement & $\begin{array}{l}\text { Food supplement that } \\
\text { contains } \\
\text { ingredients for a restful } \\
\text { sleep }\end{array}$ & $\begin{array}{l}\text { by balancing the } \\
\text { excreted level of the } \\
\text { melatonin in the } \\
\text { body }\end{array}$ & $\begin{array}{l}\text { by balancing the } \\
\text { excreted level of } \\
\text { the aldosterone in } \\
\text { the body }\end{array}$ & $\begin{array}{l}\text { by implementing an } \\
\text { innovative DS system }\end{array}$ \\
\hline Drops & $\begin{array}{l}\text { Drops that include a } \\
\text { mixture of ingredients that } \\
\text { strengthen the immune } \\
\text { system }\end{array}$ & $\begin{array}{l}\text { by increasing } \\
\text { cortisol secretion }\end{array}$ & $\begin{array}{l}\text { by increasing } \\
\text { prolactin secretion }\end{array}$ & $\begin{array}{l}\text { by using LE unique } \\
\text { component }\end{array}$ \\
\hline
\end{tabular}

\footnotetext{
${ }^{2}$ To control for the possibility that the CMs outperformed PE in study 1 due to being specific for the focal product, whereas the PEs are general and can be suitable for each product, we also made the PEs "specific" in study 2.

3 True or false was according the Wikipedia.
} 


\subsubsection{Measures}

We used the same measures as in study 1 (adapted to the products).

\subsection{Results}

Table 4 and Figures 2a, b, and c present the means of the four experimental conditions (TM, FM, PE, and CA) for each of the measures: reasonability (manipulation check), understanding and willingness to buy (dependent variables), and fit with previous knowledge (the proposed mediator). We examined hypotheses 4 and 5 by using t-tests for paired samples (see Table 4).

Table 4 Study 2. Means (and standard deviations) of the four experimental conditions (TM, FM, PE, CA) in reasonability, understanding, willingness to buy, and fit with previous knowledge

\begin{tabular}{|c|c|c|c|c|}
\hline & Manipulation & Dependent variables & & Mediator \\
\hline & $\begin{array}{l}\text { Reasonability } \\
\text { M (SD) }\end{array}$ & $\begin{array}{l}\text { Sense } \\
\text { Understanding } \\
\mathrm{M}(\mathrm{SD})\end{array}$ & $\begin{array}{l}\text { Willingness } \\
\text { to Purchase } \\
\text { M (SD) }\end{array}$ & $\begin{array}{l}\text { Fit with Previous } \\
\text { Knowledge } \\
\text { M (SD) }\end{array}$ \\
\hline $\mathrm{TM}$ & $3.55(1.49)$ & $3.68(1.58)$ & $3.35(1.51)$ & $3.79(1.41)$ \\
\hline FM & $3.57(1.39)$ & $4.08(1.41)$ & $3.44(1.47)$ & $3.48(1.39)$ \\
\hline $\mathrm{PE}$ & $3.08(1.38)$ & 3.13 (1.69) & $2.93(1.54)$ & $3.05(1.44)$ \\
\hline $\mathrm{CA}$ & \#3.21 (1.53) & $2.94(1.72)$ & $2.91(1.51)$ & \#3.14 (1.52) \\
\hline $\mathrm{F}(1,99)\left(\mathrm{eta}^{2}\right)$ & $11.69 * * *(.106)$ & $42.51 * * *(.300)$ & $15.16 * * *(.133)$ & $10.46^{* *}(.149)$ \\
\hline $\mathrm{t}$ test pairs & $\mathrm{t}(98)$ & $\mathrm{t}(98)$ & $\mathrm{t}(98)$ & $\mathrm{t}(98)$ \\
\hline TM vs FM & 0 & $2.35^{*}$ & 0 & $2.28 *$ \\
\hline CA vs PE & 0 & 0 & 0 & 0 \\
\hline $\begin{array}{l}\mathrm{TM}>\mathrm{CA} \\
\mathrm{TM}>\mathrm{PE}\end{array}$ & $\begin{array}{l}1.77 * \\
2.93 * *\end{array}$ & $\begin{array}{l}3.65 * * \\
3.08 * *\end{array}$ & $\begin{array}{l}2.57 * \\
3.03 * *\end{array}$ & $\begin{array}{l}3.52 * * * \\
5.01 * * *\end{array}$ \\
\hline $\begin{array}{l}\mathrm{FM}>\mathrm{CA} \\
\mathrm{FM}>\mathrm{PE}\end{array}$ & $\begin{array}{l}2.21 * \\
2.99 * *\end{array}$ & $\begin{array}{l}5.87 * * * \\
5.38 * * *\end{array}$ & $\begin{array}{l}3.33 * * * \\
2.91 * *\end{array}$ & $\begin{array}{l}2.05 * \\
2.99 * *\end{array}$ \\
\hline t-tests summery & $\mathrm{FM}=\mathrm{TM}>\mathrm{CA}=\mathrm{PE}$ & $\mathrm{FM}>\mathrm{TM}>\mathrm{PE}=\mathrm{CA}$ & $\mathrm{FM}=\mathrm{TM}>\mathrm{CA}=\mathrm{PE}$ & $\mathrm{TM}>\mathrm{FM}>\mathrm{CA}=\mathrm{PE}$ \\
\hline
\end{tabular}

$* p<.05 * * *, p<.001$, \# not relevant, because a claim is not "not reasonable" or contradicts previous knowledge. We include these means in the table to provide all of the data.

a.

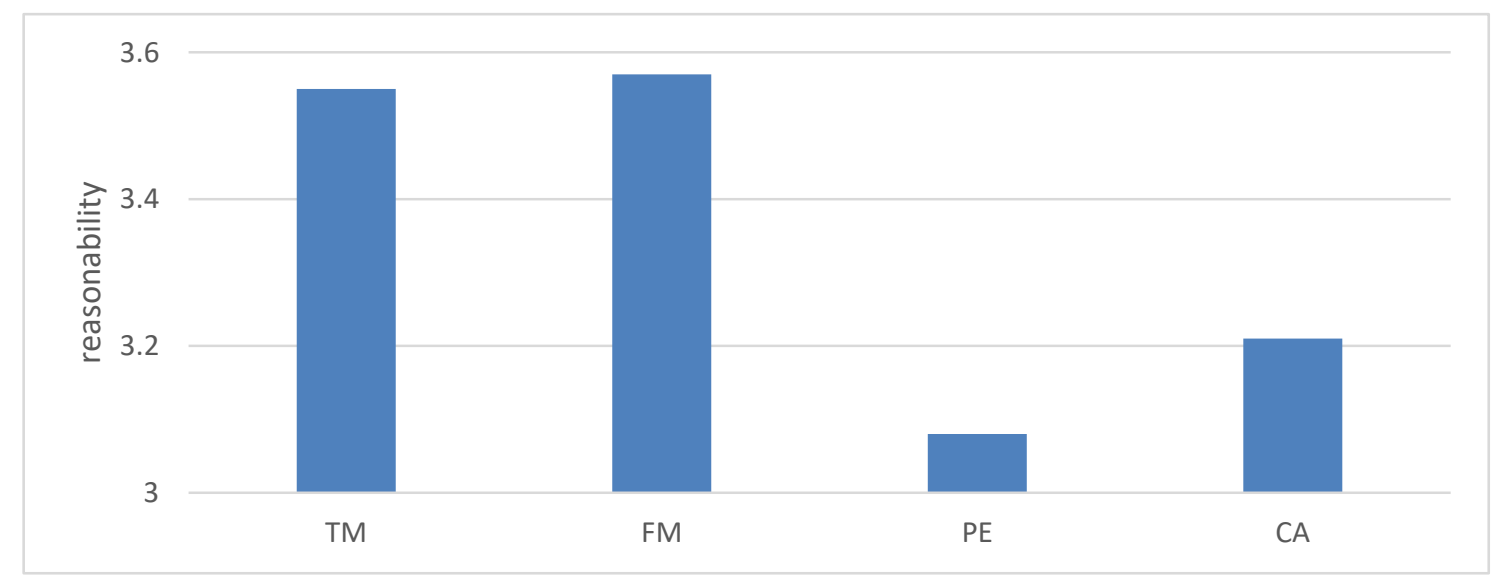


b.

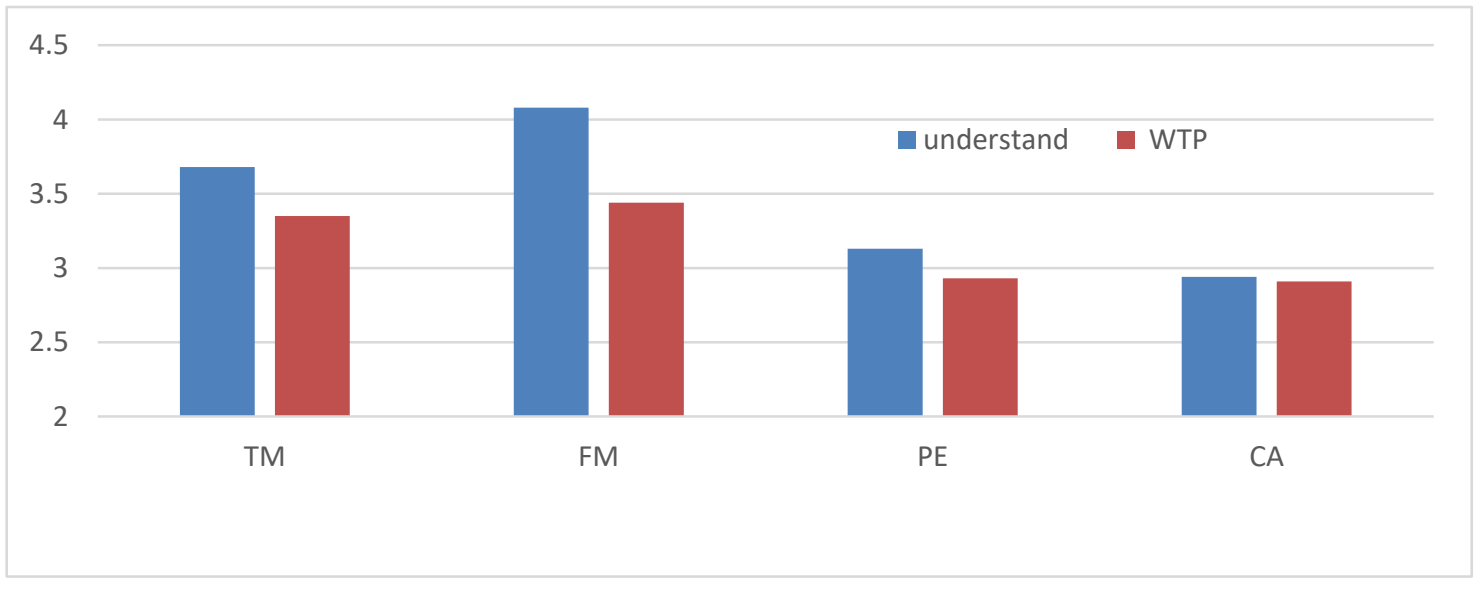

c.

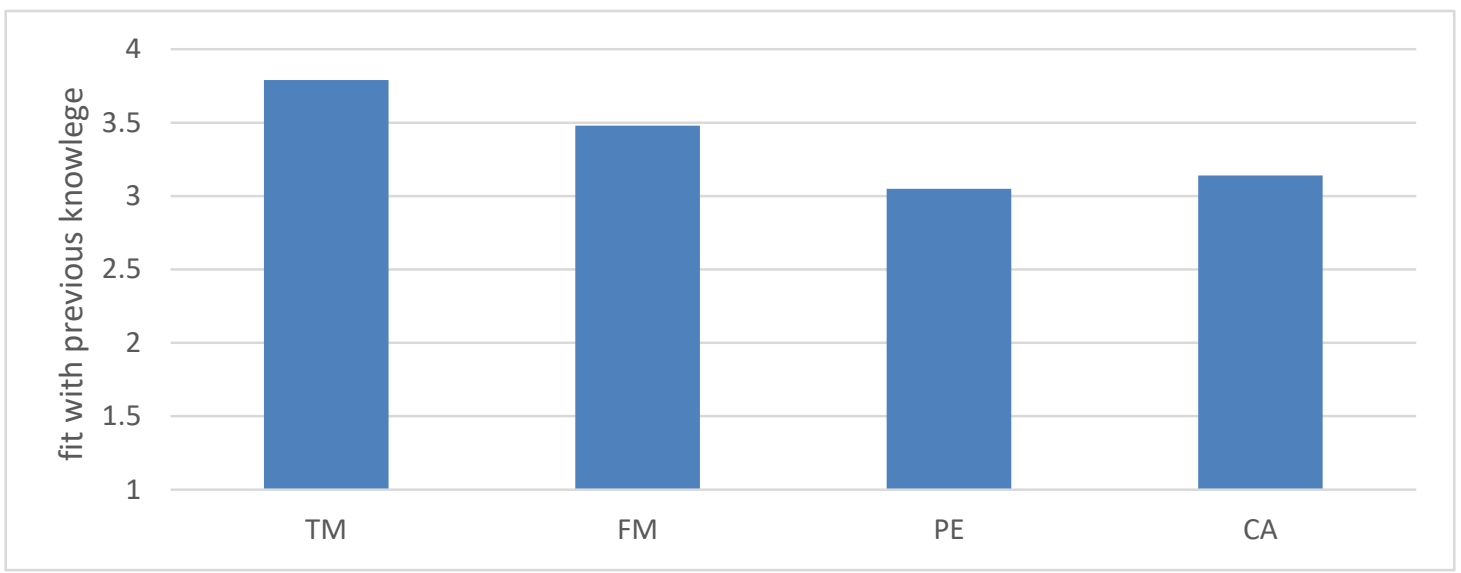

Figure 2. Ratings of reasonability (a), understanding and willingness to purchase (b), and fit with previous knowledge (c), as a function of kind of information

\subsubsection{Manipulation Check and Fit With Previous Knowledge}

As expected (see Table 4 and Figures 1a and 1c), the results show that participants perceived claims that contained an unknown mechanism (whether false or true) as more reasonable and as a better fit with previous knowledge than PE or CA. In addition, as expected, we found no difference between the two explanations that contained any mechanism and between PE and CA. Thus, providing participants with explanations that included specific mechanisms, whether true or false, seems to have been persuasive because they included scientific terms.

\subsubsection{Hypotheses 3 and 4}

As can be seen in Table 4 (and Figure 2b), as predicted (hypothesis 4), sense of understanding and willingness to purchase the product were higher when the causal claim provided any mechanism (true or false) than for PE and CA. Also, as predicted (hypothesis 5), no difference emerged between the TM an FM, and between PE and CA. Interestingly, sometimes the means were higher for FM than for TM, a result that attests to the fact that sounding scientific is enough to persuade.

\subsection{Discussion}

The results of Study 2 demonstrate that for unfamiliar systems, people are persuaded when provided a mechanism that sounds scientific even if it is false. In addition, PEs, even when we made them specific, added nothing over CA and were less persuasive than the claims including an explanation that used scientific mechanisms.

\section{Study 3}

Studies 1 and 2 demonstrated that consumers are more persuaded by causal messages that include the mechanism (by which the product produces the effect) than when they include PEs (and CAs). Yet marketers rarely provide mechanistic explanations and often provide PEs. The question is then whether this mismatch results from the perspective taken. Specifically, the question is whether adopting a marketer's perspective results in an impression that PEs are more (or at 
least as) persuasive than mechanistic explanations due to having the flavor of being innovative and technological. We designed study 3 to check this possibility. We asked 99 participants to take the position of an advertiser and to consider two messages, PE and the corresponding mechanical message (CM from study 1, and TM and FM from study 2). Then, we asked them to choose which they saw as more persuasive and thus would prefer for advertising.

\subsection{Method}

\subsubsection{Participants and Design}

Ninety-nine undergraduates $($ males $=49 \%$, Mage $=42.71$; SDage $=15.68)$ took part in the study via a Qualtrics web-based questionnaire for a small amount of money, in a within-subjects design of kind of message preferred: PE or mechanistic.

\subsubsection{Materials, Measures, and Procedure}

Each participant read the descriptions of the same nine products of studies 1 and 2. After reading the two messages possible for each product (with mechanistic explanation or PE), they chose which they found more persuasive and thus preferred to advertise. To check if mechanistic messages sound more explanatory but less innovative than PEs, we asked participants to indicate which of the two messages sounded "more explanatory" and in which of the two messages the product sounded "more innovative."

\subsection{Results}

Table 5 presents the means and standard deviations of the percentage of times the participants preferred the mechanistic messages as the advertising message, the percentage of times participants perceived them as more explanatory, and the percentage of times the product seemed more innovative.

Table 5. Means and (standard deviations) of percentage of times the participants preferred the mechanistic messages as the advertising message, the percentage of times participants perceived them as more explanatory, and the percentage of times the product seemed more innovative

\begin{tabular}{|l|l|l|}
\hline Mechanistic Messages & Mean & SD \\
\hline Preferred for Advertising & 59.21 & 27.85 \\
\hline Seem More Explanatory & 72.51 & 35.16 \\
\hline Seem More Innovative & 37.81 & 38.11 \\
\hline
\end{tabular}

As can be seen in Table 5, participants usually preferred the mechanistic message (on PE) for advertising (about 59\%) and perceived it as more explanatory (about 73\%). Yet most of the time, the products in PE messages were perceived as more innovative (about 62\%). The fact that preference for advertising of the mechanistic message was lower than its perception as more explanatory (59\% vs. $73 \%$ ) may signify the fact that marketers, when considering what message to advertise, consider not only the explanatory power, but also other factors, such as the innovation flavor.

\section{General Discussion}

Using technological terms to persuade consumers is a common practice in marketing communication. Yet no extant studies examine the persuasive impact of marketing messages that include technological terms. In two studies, we tried to answer this question by comparing explanations that use general technological words (PE) with no explanation at all (CA) and explanations that provide a specific scientific mechanism. In general, the results show PEs were no better than $\mathrm{CA}$ and were inferior to explanations that provide a scientific mechanism.

\subsection{Pseudo Explanations and Mechanistic Explanations}

\subsubsection{Definition}

We call causal messages that include general technological terms pseudo explanations because they do not really explain the mechanism by which the product produces the benefit. A short mechanistic explanation includes the cause, the effect, and one mediator variable that specifies the mechanism by which the cause produces the effect (cause -> mechanism (=mediator variable) -> effect). PEs follow the same structure, but because the proposed mediator variable (the technological term) is general, it lacks one of the basic properties that characterize mechanistic explanationscontent specificity (Ahn et al., 1995).

\subsubsection{Pseudo Explanations vs. Claim Alone}

The results demonstrate that PEs, add nothing to persuasion, do not harm to just stating the claim (CA). The question is then whether to use general technological terms as a way to "explain" how the product works. Although PEs are no better than CA, the results of study 3 indicate using them results in providing the sense that the consumer is dealing 
with an innovative product that has a High-Tech aroma. Thus, the advertiser should perhaps use them.

\subsubsection{Pseudo Explanations vs. Mechanistic Explanations}

Study 3 also shows marketers do not perceive messages that include technological terms (PE) as explanations. Although PEs follow the same structure as mechanistic explanations, participants seemed to feel the similarity was superficial.

They were not "tempted" to see them as mechanistic explanations, probably because they were not content specific. Consequently, in general, PEs are less persuasive than mechanistic explanations.

\subsubsection{Mechanistic Explanations and Previous Causal Beliefs}

Study 1 demonstrate that for systems for which consumers have some previous causal beliefs, persuasion is higher for mechanistic explanations than for PEs, but only when the explanation is congruent with the previous causal knowledge, whereas when the explanation is incongruent, mechanistic explanations are as bad as PEs. Thus, explaining that a certain product produces alertness by stimulating the nervous system may be persuasive because of previously held causal beliefs that alertness is somehow connected to the nervous system. Alternatively, explaining that the product produces alertness by stimulating the skeletal system may not be persuasive, because consumers hold no previous beliefs that alertness and the skeletal system are connected.

Yet in cases in which people hold no causal previous beliefs about the focal systems, they may fall into a trap. Specifically, the results of study 2 demonstrate that consumers perceive a message that includes a mechanistic explanation that is not relevant for the focal system, and thus cannot explain the way the product produces the effect, as an explanation and consequentially are persuaded by it. For example, a message that explains, "The magic egg increases the shelf life of fruits and vegetables by absorbing the ethylene gas they emit" is true, but the explanation that the magic egg does so "by absorbing the prion gas they emit" is not true. Vegetables and fruits do not emit prion gas and do emit ethylene gas, which is what causes them to ripen. Yet persuasion was the same in both cases and higher than CA and PE.

In fact, all the mechanistic explanations in study 2 included unknown scientific terms. The fact that no difference in persuasion arose between the true and the false mechanistic explanation, and that both were more persuasive than CA and PE, may attest to the appeal of scientific terms, and is in line with studies showing neuroscience explanations have a "seductive allure" (Weisberg, Taylor, \& Hopkins, 2015; Giattino, Kwong, Rafetto, \& Farahany, 2019).

\subsection{Individual Differences in the Impact of the Kind of Information (PE, CA, and Mechanistic Explanations)}

In studies 1 and 2, we measured the processing-information style by using rational-experiential inventory (Epstein et al., 1996) and skepticism toward advertising (Obermiller \& Spangenberg, 1998), but for conciseness, we do not report all of the findings here. We wanted to check whether information-processing style and skepticism toward advertising have an attenuating impact of the kind of information on persuasion. For example, one could expect participants whose dominant information-processing style is experiential (are less skeptical toward advertising) to be more persuaded by PEs than participants whose dominant information-processing style is rational (are more skeptical toward advertising). Similarly, one could expect participants whose dominant information-processing style is experiential (are less skeptical toward advertising) to be more persuaded by mechanical explanations that are false than participants whose dominant information-processing style is rational (are more skeptical toward advertising). In both studies (1 and 2), the interactions between the kind of information and processing style (skeptical toward advertising) were far from significant, attesting to the robustness of the finding that PE is less persuasive than a mechanistic explanation.

\subsection{The Prevalence of Using PE vs. Mechanistic Explanation in Advertising}

As mentioned before, in marketing communication, a common practice is to provide PEs, whereas mechanistic explanations are rare, despite the fact that mechanistic-explanations have many positive effects, including on persuasion. Why, then, do advertisers often provide PEs and not mechanistic explanations?

We can think of several reasons. First, advertisers usually lack the information on the mechanism. To understand how a product produces the effect, they must exert considerable effort, such as to find the specific mechanism, to understand how it works and to find the best short way to explain it to the consumer. Moreover, because most people feel they are far from being experts in understanding how products produce benefits, marketers prefer to avoid explaining something they are far from being sure about. Thus, an easy way out for marketers would be to provide pseudo explanations.

General technological terms are not content specific, and thus marketers can use them in almost any content. Therefore, using PEs not only prevents marketers from needing to search for the correct and suitable mechanism, without being committed, but also seems innovative and technological (as we saw in the results of study 3 ). In any case, using PEs is better than taking advantage of consumer vulnerability to scientific terms and providing mechanistic explanations that are false. 


\section{References}

Ahn, W., Kalish, C. W., Medin, D. L., \& Gelman, S. A. (1995). The role of covariation versus mechanism information in causal attribution. Cognition, 54, 299-352. https://doi.org/10.1016/0010-0277(94)00640-7

Ahn, W., Novick, L., \& Kim, N. S. (2003). Understanding it makes it more normal. Psychological Bulletin Review, 10, 746-752. https://doi.org/10.3758/BF03196541

Anderson, C. A., Lepper, M. R., \& Ross, L. (1980). Perseverance of social theories: The role of explanation in the persistence of discredited information. Journal of Personality and Social Psychology, 39(6), 1037-1049. https://doi.org/10.1037/h0077720

Einhorn, H. J., \& Hogarth, R. M. (1986). Judging probable cause. Psychological Bulletin, 99, 1-19. https://doi.org/10.1037/0033-2909.99.1.3

Epstein, S., Pacini, R., Denes-Raj, V., \& Heier, H. (1996). Individual differences in intuitive-experiential and analyticalrational thinking styles. Journal of Personality and Social Psychology, 71(2), 390-405.

Fernbach, P. M., Sloman, S. A., Louis, R. S., \& Shube, J. N. (2013). Explanation friends and foes: How mechanistic detail determines understanding and preference. Journal of Consumer Research, 39(5), 1115-1131. https://doi.org/10.1086/667782

Giattino, C. M., Kwong, L., Rafetto, C., \& Farahany, N. A. (2019). The Seductive Allure of Artificial Intelligence-Powered Neurotechnology. https://doi.org/10.1145/3306618.3314269

Glassner, A., Weinstock, M., \& Neuman, Y. (2005). Pupils' evaluation and generation of evidence and explanation in argumentation. British Journal of Educational Psychology, 75(1), $105-118$. https://doi.org/10.1348/000709904X22278

Gopnik, A. (2000) Explanation as orgasm and the drive for causal knowledge: the function, evolution, and phenomenology of the theory formation system. In Explanation and Cognition (Keil, F. and Wilson, R.A., eds), pp. 299-324, MIT Press.

Hayes, A. F. (2013). Introduction to mediation, moderation, and conditional process analysis: A regression-based approach. New York: Guilford.

https://doi.org/10.1037/0022-3514.71.2.390

Kendeou, P., \& van den Broek, P. (2007). The effects of prior knowledge and text structure on comprehension processes during reading of scientific texts. Memory \& Cognition, 35(7), 1567-1577. https://doi.org/10.3758/BF03193491

Kuhn, D. (2001) How do people know? Psychological Science, 12, 1-8. https://doi.org/10.1111/1467-9280.00302

Lombrozo, T. (2006). The structure and function of explanations. Trends in Cognitive Sciences, 10(10), 464-470. https://doi.org/10.1016/j.tics.2006.08.004

Murphy, G. L., \& Medin, D. L. (1985). The role of theories in conceptual coherence. Psychological Review, 92(3), 289-316. https://doi.org/10.1037/0033-295X.92.3.289

Obermiller, C., \& Spangenberg, E. R. (1998). Development of a scale to measure consumer skepticism toward advertising. Journal of Consumer Psychology. https://doi.org/10.1207/s15327663jcp0702_03

Patalano, A. L., Chin-Parker, S., \& Ross, B. H. (2006). The importance of being coherent: Category coherence, cross-classification, and reasoning. Journal of Memory \& Language, 54, 407-424. https://doi.org/10.1016/j.jml.2005.10.005

Saporta-Sorozon, K. (2018). "God is in the Details": The effect of directional verbs in process explanations on text coherence. Global Journal of Management and Business Research: E Marketing, 18(1), 1-13.

Walsh, C. R., \& Steven, A. (2011). The Meaning of Cause and Prevent: The Role of Causal Mechanism. Mind and Language, 26(February), 21-52. https://doi.org/10.1111/j.1468-0017.2010.01409.x

Weisberg, D. S., Taylor, J. C., \& Hopkins, E. J. (2015). Deconstructing the seductive allure of neuroscience explanations. Judgment and Decision making, 10(5), 429.

\section{Copyrights}

Copyright for this article is retained by the author(s), with first publication rights granted to the journal.

This is an open-access article distributed under the terms and conditions of the Creative Commons Attribution license which permits unrestricted use, distribution, and reproduction in any medium, provided the original work is properly cited. 